\title{
Fanatismo: interés en psiquiatría forense penal
}

\section{Fanatism: interest in criminal forensic psychiatry}

\section{Resumen}

En el presente trabajo describimos el fanatismo desde una doble dimensión, la cognitiva y la personológica y vemos el carácter gradual de este fenómeno. Desde estos presupuestos conceptuales planteamos las posibles anomalías que pueden hallarse en el continuum sujeto/creencia normal - sujeto/creencia fanático y como tales alteraciones podrían afectar a la capacidad de responder penalmente de estas personas. Para ello deben ser comprendidas las distorsiones cognitivas que suponen la creencia fanática y las eventuales anomalías en la estructura de la personalidad del sujeto fanático.

Palabras clave: Fanatismo. Creencias. Distorsiones cognitivas. Alteraciones de la personalidad.

\section{Abstract}

This paper describes the fanatism from two viewpoints, cognitive and personological and looks at the progressive nature of this phenomenon. Based on these conceptual hypotheses, we present the anomalies which may be found in the continuum of subject/normal belief - subject/ fanatical belief and how these changes affect the capacity of these individuals to respond criminally. This requires the understanding of the cognitive disturbances implied by fanatical belief and the potential anomalies in the structure of the fanatical subject's personality.

Key words: Fanatism. Beliefs. Cognitive disturbances. Personality disorders.

\section{Aspectos conceptuales del fanatismo}

\section{Definición}

Según el Diccionario de la Real Academia de la Lengua Española, se define como fanática aquella persona que defiende con tenacidad desmedida y apasionamiento creencias u opiniones, sobre todo religiosas o políticas. Para de la Corte ${ }^{1}$, el fanatismo es un estado mental caracterizado por la adhesión tenaz y prolongada a ciertas creencias. En el mundo mental del fanático, una o varias creencias adquieren una importancia muy superior a las demás, hasta el punto de transformarse en la mayoría de sus actos. Alonso Fernández ${ }^{2}$ considera fanáticos a los que entregan toda su facultad de creer o creditividad, de un modo absoluto e incondicional, a un tema o a una cuestión, con intolerancia sistemática para los juicios y comportamientos discrepantes ${ }^{3}$.

Para Javaloy ${ }^{4}$, el fanatismo supone una intensa adhesión afectiva a una idea, socialmente compartida, a la que se concede un valor absoluto, que pretende ser realizada destruyendo cualquier obstáculo que se le interponga.

Alonso Fernández ${ }^{1}$ describe el fanático idealista combativo como un "iluminado violento" que posee un "ideal sobrevalorado" que se eleva a la categoría de dogma absoluto, con gran carga afectiva que le hace deformar las experiencias y situaciones (catatimia).

Nosotros encontramos una doble dimensión del fanatismo: la dimensión cognitiva y la dimensión

\section{A. Villarejo}

Médico Forense del Instituto de Medicina Legal de Cádiz.

Especialista Universitario en Psiquiatría Legal y Forense.

Especialista en Medicina Legal y Forense.

Correspondencia: Dr. Alberto Villarejo. E-mail: alberto.villarejo@juntadeandalucía.es
Fecha de recepción: 23.ENE.2010

Fecha de aceptación: 22.FEB.2010 
personológica, ambas en íntima relación, pues las creencias forman parte del mismo ser humano, el sistema de nuestras creencias "es lo que somos", como afirmaba Ortega y Gasset ${ }^{5}$.

En este sentido García de Haro ${ }^{6}$ resalta que "la importancia de las creencias en la mente humana no pude comprenderse si sólo se tiene en cuenta su aspecto cognitivo... Las creencias son sobre todo la creación de un mundo y de una manera de ser". El creyente, para este autor, no sólo piensa que el mundo externo es de tal o cual manera, sino que él mismo queda transformado por su creencia. También él se interpreta a sí mismo y de tal forma que adquiere otra naturaleza, se hace un ser distinto que piensa, siente y actúa de manera diferente.

Siguiendo a la escuela cognitiva, la personalidad es el resultado de las creencias del sujeto, conformando un estilo de vida que otorgan validez y perpetúan estas creencias ${ }^{7}$.

\section{Bidimensionalidad}

\section{Dimensión cognitiva: el pensamiento fanático}

La dimensión cognitiva del fanatismo está constituida por el conjunto de ideas con determinadas características y creencias que hace suyas el sujeto fanático.

Según Javaloy ${ }^{5}$, la idea propia del fanático se caracteriza por ser absoluta, infalible, eterna, predestinada a vencer, norma suprema de acción a obedecer. Decreta aquello que es verdadero e irremplazable, ejerce un efecto sustractor de la mente a cualquier idea diferente que intente surgir ${ }^{8}$. Está marcada por la afectividad y, por tanto, ajena a argumentos racionales y objetivos fundamentados en la realidad y abomina, como asegura Alonso-Fernánde $z^{3}$ del pensamiento lógico-racional. Su fundamento es emocional o mágico-religioso ${ }^{9}$.

La idea fanática o dogma se caracteriza, para Sor, citado por Ramírez Coronel ${ }^{10}$, por quedar aislada de la duda y de la hermandad con otras ideas; de esa manera, en el mundo interno y en la experiencia del individuo de desaloja al misterio, ya no tiene que averiguar nada, porque ya lo sabe todo y se impone una conclusión.

El pensamiento fanático es concreto y dicotómico, sin matices ni discriminaciones ${ }^{3}$, donde las ideas se han maximizado, sacralizado ${ }^{4}$, transformado en creencias que no admiten examen y excluyen la libertad de pensar.
Como vemos, el pensamiento fanático se sustenta sobre creencias, pero las creencias forman parte de la realidad cognitiva normal de la mayoría de las personas, podemos hablar por tanto de una cierta normalidad del pensamiento fanático.

\section{Normalidad del pensamiento fanático}

Como aseguraba Ortega y Gasset ${ }^{5}$ “.... no hay vida humana que no esté, desde luego constituida sobre ciertas creencias básicas y, por decirlo así, montada sobre ellas", "... constituyen el continente de nuestra vida", "son nuestro mundo y nuestro ser", "el terreno sobre el que acontece toda nuestra conducta, incluso la intelectual, depende de cuál sea el sistema de nuestras creencias auténticas", "a ellas estamos inseparablemente unidos".

Kruglanski, citado por de la Corte ${ }^{1}$, supone que la firmeza con que cualquier persona corriente sostiene algunas de sus opiniones o creencias se parece bastante a la del fanático. El autor advierte que si los seres humanos no sintiéramos nunca la necesidad de aislarnos de los flujos de información al que nos vemos expuestos y de interrumpir y poner término a nuestros procesos de reflexión, viviríamos en un estado de parálisis permanente, escasamente adaptativo (una especie de "parálisis por análisis"). Por ello, asegura de la Corte, experimentamos a diario la necesidad subjetiva de experimentar ideas claras y firmes respecto a ciertos asuntos personales 0 circunstancialmente relevantes. A esta actitud la ha denominado Kruglanski "cierre cognitivo".

Para Díez Patricio ${ }^{11}$, el entendimiento humano utiliza normalmente mecanismos cognitivos heurísticos, mediante los cuales se reduce la incertidumbre derivada de la limitada capacidad cognitiva humana, restringiendo los problemas a una dimensión manejable por el sistema cognitivo. Siendo excepcional el uso de procedimientos cognitivos analíticos. Según el autor, el razonamiento más frecuente se caracteriza por que:

- Las actitudes, creencias y expectativas del sujeto determinan su manera de razonar.

- Existe una tendencia natural en el sujeto a negar los hechos que refutan sus interpretaciones y a aceptar aquellos que los confirman.

- Cuando un sujeto sostiene una hipótesis, toda nueva información que sea contradictoria con ella es escasamente eficaz para modificarla.

- Si el sujeto sostiene fuertes expectativas sobre algo suele pasar por alto las evidencias que chocan con ellas. 


\section{Dimensión personológica: la personalidad fanática}

Kurt Schneider en 1923 describió los "psicópatas fanáticos" en su libro Personalidades psicopáticas y les atribuía rasgos paranoides y Millon ${ }^{7}$, más recientemente, describe un subtipo de paranoide fanático que asume la identidad de un líder noble inspirado, una figura política poderosa que se propone misiones grandiosas para salvar el mundo, etc., con rasgos muy similares a los de la personalidad narcisista.

Sin embargo, en la actualidad ninguna de las clasificaciones nosográficas (CIE X o DSM IV TR) reconoce el fanatismo como un trastorno de la personalidad. En efecto, no parece estar clara la relación del fanatismo con un constructo definido de personalidad. De la Corte no encuentra entre los terroristas unos rasgos específicos, y en este mismo sentido se expresa Alonso Fernández quien, no obstante, define una estructura parcial en la personalidad en estos sujetos, un "eje fanático" que el autor denomina "fanático idealista combativo" que interviene en los momentos de erupción del fanatismo ${ }^{2}$.

Otros autores consideran que existen diferencias de personalidad entre los líderes fanáticos y los adeptos. Así, Post (citado por de la Corte) ${ }^{1}$, describe rasgos de narcisismo, psicopatía y visión paranoica del mundo en los líderes fanáticos, Alonso Fernández ${ }^{2}$ encuentra rasgos narcisistas autoritarios y E. Fromm ${ }^{12}$ halla un carácter autoritario sadomasoquista en los dictadores.

Por el contrario, entre los adeptos fanáticos predominan los radicales de inseguridad, inmadurez, carencia de identidad y dependencia emocional ${ }^{13}$ o bien rasgos narcisistas, psicopáticos ${ }^{3}$ con alta impulsividad y búsqueda de emociones fuertes 0 paranoides ${ }^{13}$ en sujetos fanatizados secundariamente. Estas mismas características que diferencian a los líderes fanáticos de los adeptos las describe Alonso Fernández ${ }^{2}$ en su clasificación entre fanáticos primarios y secundarios.

Por nuestra parte, si estudiamos los distintos ámbitos que conforman la estructura de la personalidad propuestos por Millon, creemos que es posible encontrar la mayoría de los siguientes rasgos en un importante número de personas fanáticas:

\section{Autoimagen: combativa}

La mayoría de los sujetos fanáticos se muestran egosintónicos y se ven a sí mismos como personas asertivas, arrogantes, altaneras, enérgicas $y$ autoconfiadas, pero sinceros, fuertes y realistas y prefieren dar una imagen de dureza, falta de sentimientos, belicosa dominante y orientada al poder, coincidiendo con las personalidades sádicas descritas por Millon?

Se sienten orgullosos de sus ideas ${ }^{1}$ y son, como los paranoides, reacios a confiar o depender de los otros y tienen un sentido combativo y tenaz de los propios derechos al margen de la realidad. Impregnados, al igual que el sujeto antisocial, de la creencia de la superioridad moral de sus ideas políticas o religiosas ${ }^{1}$, tratan de imponérsela a los demás, para lo que no dudan en emplear métodos coactivos, combativos o violentos.

\section{Estilo cognitivo: dogmático y dicotómico}

Su rigidez y obstinación hacen que estos sujetos tiendan a mantener de forma pertinaz sus prejuicios y son incapaces de cambiar de opinión, mostrándose intransigentes con puntos de vista disidentes. Se muestran intolerantes, en especial con grupos sociales, étnicos ${ }^{14}$ o raciales, característica que comparten con los sádicos de Millon. No son capaces de percibir los distintos matices de la realidad compleja, encontrando sólo, con una visión dicotómica, los extremos opuestos de ésta.

Estos rasgos coinciden con la descripción del fanático idealista combativo de Alonso Fernández ${ }^{2}$, al que describe como un iluminado violento convencido de poseer la verdad en la esfera política, religiosa o nacionalista en forma de un sistema de ideas cerrado y elevado a la categoría de dogma absoluto. Es incapaz de desarrollar pensamientos sujetos a matices y discriminaciones.

Kruglanski, citado por de la Corte $^{1}$, encuentra en el fanático una intensa aversión a cualquier estado psicológico de ambigüedad e incertidumbre, que se traduce en dos efectos complementarios: a) una predisposición favorable hacia las ideas y sistemas de creencias claros y sencillos, y b) la tendencia a "congelar las propias creencias y opiniones para mantenerlas intactas "cerrando las puertas de la mente" al tráfico de ideas e informaciones que habitualmente se derivan de la interacción social.

Pero también, al igual que los narcisistas, son expansivos, con tendencia a sobrestimar sus propios recursos, capacidades y posibilidades de éxito ${ }^{1}$, a veces de forma fantasiosa.

\section{Comportamiento observable: suspicaz/explosivo}

Se comportan como los paranoides, con suspicacia extrema, con desconfianza hacia las intenciones de los demás que le hacen presentar actitudes defensivas y hostiles frente al mundo. Preocupados por conspiraciones, consideran al extraño como el depositario de todos los males propios. 
Adolecen de pobreza afectiva, pero son irascibles y con alta impulsividad, por lo que tienen predisposición a reaccionar con explosiones emocionales súbitas y bruscas de naturaleza inesperada e injustificada ${ }^{15}$.

\section{Comportamiento interpersonal: extrapunitivo/sumiso}

Despectivos y despreciativos ${ }^{2}$ obtienen, al igual que los sádicos, satisfacción de la humillación, coacción e intimidación de los otros. Con ausencia de empatía para sensibilizarse con el sufrimiento ajeno y desprecio a la naturaleza humana ${ }^{14}$, no sienten, como los antisociales, remordimientos cuando generan daño en los otros, a quienes suelen ver como enemigos ${ }^{13}$.

Tenaces ${ }^{1}$, obstinados y muy comprometidos y responsabilizados con la causa que defienden, cuando se violan algunos de estos valores muestran una disposición evidente al castigo. Sus impulsos a la actividad, como asegura Alonso Fernández, están regulados por la extrapunitividad².

Su actividad está orientada hacia el poder, ejerciéndolo de forma despótica sobre sus subordinados 0 sobre las personas que consideran débiles. A la vez, se sienten fascinados por quien detenta el poder y la autoridad y adoptan, según describió E. Fromm para el carácter autoritario sadomasoquista, una actitud sumisa ante ellos o ante cualquier poder que consideren superior (Dios, el Destino, la Necesidad, la Historia, la Naturaleza, el Estado, el Pueblo, etc. $)^{12}$.

\section{Mecanismos de defensa: racionalización /sublimación}

Racionalizan sus conductas intransigentes e impositivas en forma de indignación moral, asegurando que actúan "por el bien del otro o por el bien común" y justifican sus comportamientos combativos como reacción a un ataque de los otros ${ }^{12}$. Subliman sus comportamientos agresivos y coactivos y sus creencias como imprescindibles para conseguir un fin social, religioso o político que servirá de redención de los demás o de la humanidad. Subliman, por otro lado, su actitud sumisa como lealtad a autoridades o ideologías por encima de los espurios intereses egoístas.

\section{Representaciones objetales: perniciosas}

La representación del mundo que se hace el fanático es un lugar hostil que le ha producido multitud de frustraciones personales, originando un déficit de autoestima y de las que responsabiliza a los otros $^{13}$. Al mismo tiempo, ha ido asumiendo un sistema de valores según el cual el grupo (nacional, religioso, racial, social, sexual, etc.) al que pertenece el sujeto también ha sido víctima real o imaginaria de agravios. Para resarcirse de tales afrentas individuales y colectivas el fanático adopta una actitud intransigente, impositiva y combativa, cuando no francamente violenta y destructiva.

\section{Estado de ánimo/temperamento: irascibilidad}

Las personas fanáticas son normalmente irascibles, fácilmente irritables al ser contrariados sus postulados, no siendo infrecuente la hostilidad hacia los que no piensan como ellas. No comparten verdaderos sentimientos con los demás, tan sólo empatizan con sus correligionarios en los dogmas y creencias que les unen.

\section{Organización morfológica: fragilidad del yo}

Poseen, como asegura Alonso Fernández ${ }^{2}$ un "yo" muy débil, con un "súper yo" muy rígido e inflexible en lo tocante a velar por los ideales del yo, aunque se desentiende de las inhibiciones morales, de los intereses altruistas y de las reacciones de culpabilidad.

Incapaces de sostenerse por si solos, necesitan de una relación simbiótica con otras personas, relación que se manifiesta en aptitudes sadomasoquistas al igual que la personalidad autoritaria descrita por E. Fromm ${ }^{12}$. Por un lado tratan de integrarse o convertirse en algo que consideran superior a ellos, que les libere de su propia responsabilidad (un líder, una ideología, una religión) y que les ayude a adquirir la fuerza de la que el "yo" carece y por el otro, necesitan ejercer poder sobre los demás para afirmar su autoridad. Esa misma fragilidad del yo hace que el sujeto fanático se adhiera de forma inquebrantable a creencias o ideologías que le protejan de la incertidumbre.

Interés psiquiátrico forense del fanatismo: la responsabilidad penal del sujeto fanático

El artículo 20 del vigente Código Penal Español de 1995 contempla que:

"Están exentos de responsabilidad criminal:

$1^{\circ}$. El que al tiempo de cometer la infracción penal, a causa de cualquier anomalía o alteración psíquica, no pueda comprender la ilicitud del hecho o actuar conforme a esa comprensión."

Por otra parte y siguiendo a Carrasco ${ }^{16}$, la Jurisprudencia española ha reconocido en retiradas ocasiones que los requisitos para aplicar tal eximente están basados en una cuádruple comprobación: 
- La naturaleza de la perturbación y que ésta tenga influencia sobre las capacidades cognitiva y volitiva (criterio cualitativo).

- La intensidad y grado de la perturbación (criterio cuantitativo).

- Duración del trastorno y permanencia del mismo (criterio cronológico), si bien el propio autor reconoce como irrelevantes estos aspectos temporales, concediendo más importancia a la concurrencia de la alteración psicopatológica con la acción delictiva, pues así lo exige el propio precepto, donde se lee "... al tiempo de cometer la infracción penal”.

- Relación de causalidad o de sentido entre el trastorno psíquico y el hecho delictivo.

\section{El criterio cualitativo: bidimensionalidad}

\section{Naturaleza de la anomalía}

El fanatismo, como asegura de la Corte $^{1}$, no es una enfermedad mental y no figura entre las categorías diagnósticas contendidas en el DSM IV TR. No obstante ipodemos encontrar en el fanático alguna "anomalía o alteración psíquica" a las que hace referencia el Código Penal?

¿Existen en las creencias del fanático o en su personalidad algunos elementos que podamos considerar anómalos? ¿Son las ideas fanáticas absolutamente normales o pueden obedecer a mecanismos cognitivos distorsionados? ¿Se pueden encontrar en la personalidad del fanático funciones o estructuras que provoquen una interpretación errónea de la realidad, que usen mecanismos de defensa rígidos e inflexibles, que pongan en juego afectos desbordados, que presenten motivaciones indeseadas o que determinen comportamientos desadaptados?

Creemos que, más allá de un diagnóstico clínico de enfermedad mental o trastorno de la personalidad, se han de explorar todas aquellas funciones y estructuras del fanático que determinarán su personalidad y sus conductas y que puedan suponer una influencia en las capacidades cognitiva y volitiva del sujeto. Nos referimos a los aspectos cognitivos, afectivos, temperamentales, de autoconcepto ${ }^{17}$, a los mecanismos de defensa y motivaciones (como proceso de interiorización de valores y de comportarse según los mismos) ${ }^{18}$, en interactuación con los elementos ambientales ${ }^{19}$.

\section{Alteración de la capacidad cognitiva}

El Código Penal hace referencia a la incapacidad para comprender "la ilicitud del hecho". Desde un punto de vista estrictamente intelectivo, es obvio que las personas fanáticas conocen la legalidad o ilegalidad de sus actos.

Sin embargo, en la función cognitiva interviene además, como hemos apuntado en otro trabajo ${ }^{18}$, la forma que tiene el sujeto de dirigir su atención, de percibir, de interpretar lo percibido y de actuar sobre la base de dichas interpretaciones.

En este sentido, de la Corte $^{1}$ escribe que la mentalidad fanática es proclive a incurrir en graves distorsiones de percepción y pensamiento. Estas distorsiones se caracterizan por a) una enorme selectividad a la hora de buscar, captar y recordar información acerca de la realidad social circundante, dando prioridad absoluta a aquella información que es congruente con sus actitudes, valores y creencias, y b) tendencia al autoengaño (respecto a los propios defectos y fracasos) y a incurrir en el llamado sesgo del pensamiento desiderativo (confundir la realidad con el deseo y sobreestimar las probabilidades de que las cosas salgan como uno quisiera).

El efecto final del fanatismo, según el autor, es una relativa independencia entre su forma de percibir el mundo y los hechos reales. El fanático, según Berko$w_{i e}{ }^{8}$, necesita desmentir, repudiar o incluso destruir la realidad que atente contra el sistema (de creencias). Por otra parte, el importante componente afectivo del que están revestidas las ideas del fanático coadyuva, a través de la catatimia ${ }^{3}$ en la producción de juicios distorsionados.

Pero además, como ya hemos escrito ${ }^{18}$ en la comprensión de la "ilicitud del hecho" interviene el proceso de internalización que el sujeto hace de la norma, pues no sólo ha de entender intelectualmente las reglas que rigen la sociedad en al que se desenvuelve, sino que debe hacerlas suyas y ha de sentirse motivado por ellas (Mir Puig, 1982, citado por Delgado Bueno ${ }^{19}$ ).

Si, como asegura Alonso Fernández² en muchos fanáticos se recoge desde niños la semilla formativa del credo religioso fundamentalista, la instrucción nacionalista excluyente o la pedagogía del odio y la violencia, se generará, creemos nosotros, la internalización de un sistema de valores fanatizante, con el que el sujeto se siente identificado y bajo cuyas normas actuará, al margen de las reglas sociales generales, que no habrá aprehendido. Es decir, adolecerá de una comprensión ética de las normas generales y sólo se motivará por su particular sentido ético. Como asegura Javaloy ${ }^{4}$, para el fanático el bien o el mal sólo son la obediencia o desobediencia a su causa. Por consiguiente, según Berkowiez ${ }^{8}$ el fanático jamás sentirá culpa en tanto obedece a su ideal. 


\section{Alteración de la capacidad volitiva}

En relación con la alteración de la voluntad, como causa de eximente de responsabilidad penal, hacemos un triple análisis.

Por un lado, analizamos la expresión literal de "actuar conforme a esa comprensión". Es decir, como afirma Carrasco ${ }^{16}$, no se puede querer sin previamente conocer, por tanto creemos que las distorsiones cognitivas arriba explicadas pueden perturbar el acto voluntario del fanático pues, como sostienen los teóricos cognitivos, las personas reaccionan ante su entorno según la percepción singular que tiene de éste. No importa cuan inconscientemente distorsionadas sean esas percepciones; la forma de conceptualizar los acontecimientos es la que determina el comportamiento (Millon) ${ }^{7}$.

En segundo lugar, la motivación es el factor que incita al individuo a actuar, es el impulso de la acción volitiva, por tanto, se debe considerar el sistema motivacional del sujeto ${ }^{19}$ o lo que desde el punto de vista jurídico se llama "motivabilidad" y que Mir Puig (1982), citado por el autor, define como la capacidad de motivación por la norma.

Finalmente, siguiendo a Carrasco ${ }^{16}$, pueden existir acciones ajenas a la inteligencia y la comprensión, que escapan a la reflexión, tales como los actos impulsivos, irresistibles o irrefrenables. Creemos entonces que pueden presentarse en el fanático actos más o menos impulsivos impregnados del elevado componente afectivo de muchos de estos sujetos, altamente irascibles e irritables. En ellos, como apunta Echeburua $^{15}$, se exalta el comportamiento emocional en detrimento del racional.

\section{El criterio cuantitativo: gradualidad}

Naturalmente en todos los sujetos fanáticos no encontraremos alteraciones que modifiquen sus capacidades cognitiva y volitiva. Sin embargo creemos que existe una gradualidad entre normalidad y anomalía psíquicas desde la perspectiva bidimensional cognitiva-personológica del fanatismo que hemos expuesto más arriba, en cuyo recorrido encontraremos a fanáticos sin trastornos y a otros que, en determinada medida, presentaran alguna anomalía en sus sistema de creencias o en la estructura de su personalidad, que se vuelve rígida, inflexible o inadaptativa, que influyan en las esferas cognitiva o volitiva.

En efecto, como hemos visto, las creencias forman parte de la realidad psíquica de todas las personas, sin embargo en el fanático han experimentado un proceso degradador en el que se han vuelto inamovibles e impermeables a otras opiniones, cargándose de fuertes componentes afectivos y adquiriendo una importancia desmesurada. Las creencias fanáticas exigen una entrega absoluta al portador de las mismas, quien se vuelve intolerante con cualquier otra idea. Este trayecto degenerativo supone un continuum no siempre bien delimitado entre las creencias como fenómenos normales (antes referidas), las creencias como confusión de la realidad, las creencias anormales o ideas sobrevaloradas (más propias del fanático) y las ideas delirantes. Cada una de estas ideas, según se distancien de la realidad o supongan una experiencia de certeza ${ }^{20}$ y por tanto se aproximen al ámbito de lo psicótico, pueden afectar en diferentes medidas a las capacidades cognitiva y volitiva.

\section{Creencias como confusión de la realidad}

Según García de Haro ${ }^{6}$, las creencias son la tendencia aberrante a tomar la fantasía por la realidad y a obrar en consecuencia. Ayudan al hombre a crearse una interpretación de la realidad. Todo creyente -asegura el autor-, y casi todo el mundo lo es, confunde su interpretación del mundo con la realidad. La creencia se confunde con la realidad misma.

Para el mismo autor, las creencias son automatismos cerebrales, patrones de interpretación de la realidad fijados fuertemente en el cerebro, que nos instalan en mundos irreales, con un significado afectivo muy importante para el sujeto y que nos producen una indudable sensación de realidad "...entran a formar parte de la constitución de nuestra mente, de nuestra manera de ser".

\section{Creencias anormales: ideas sobrevaloradas}

Las ideas sobrevaloradas, al decir de Calcedo ${ }^{21}$, son pensamientos de gran carga emocional. Son creencias mantenidas con convicción que se rebaten con dificultad. Ocupan un lugar preeminente en el campo de la conciencia y rigen en gran medida la actividad del pensamiento y la conducta. Son comprensibles biográfica o circunstancialmente.

Diversos autores identifican las ideas fanáticas como ideas sobrevaloradas. Por ejemplo, Echeburua ${ }^{13}$ sostiene que las creencias fanáticas constituyen ideas sobrevaloradas que ocupan un lugar muy importante en el pensamiento del fanático, impregnan afectivamente su vida y ejercen una acción tiránica sobre sus conductas. El sujeto fanático idealista luchador descrito Alonso-Fernández ${ }^{2}$ se distingue por la formación de un ideal sobrevalorado, o sea, un sistema de creencias rígido e inquebrantable vivido con una enorme pasión. El punto esencial del ideal sobrevalorado, continua el autor, es que se trata de una 
cuestión sobrecargada de afectividad, abrazada de una pasión inconmovible y que, por ello, se instala en el centro de la vida psíquica. A su vez, García Andrade $^{22}$ encuentra que en el psicópata fanático de Schneider es aquel que tiene una ideas sobrevaloradas que ejercen una acción tiránica sobre el campo de la conciencia, por su permanencia y su gran carga afectiva. Finalmente para Carrasco ${ }^{16}$ las ideas sobrevaloradas pueden estar en la base de las conductas sin reflexión y valoración crítica en personalidades con rasgos de fanatismo político o religioso.

\section{Ideas delirantes}

Como apunta Martín Cordero ${ }^{23}$, las ideas sobrevaloradas pueden formar parte de la normalidad de una serie de sujetos que padecen estados paranoideos, que pueden evolucionar hacia la paranoia.

En este sentido García de Haro escribe que el fanático se aproxima mucho a la paranoia ${ }^{6}$. El sujeto, prosigue el autor, vive con absoluta certeza su realidad delirante. Siguiendo esta línea, García Andrade ${ }^{22}$ hace notar la gradación del fanatismo y advierte de la dificultad de distinguir entre un idealista apasionado, que por sus ideales es capaz de sacrificar su vida o su porvenir, un fanático, que tiene unas ideas sobrevaloradas, o un paranoico con su vivencia delirante, puesto que, en ocasiones, es muy difícil establecer las fronteras entre unos y otros. Igualmente, para Alonso Fernández ${ }^{2}$, el fanático personal franquea la frontera con los cuadros delirantes paranoides con suma facilidad.

\section{El criterio causal. Criminalidad del fanatismo}

El criterio jurídico de causalidad nos exige determinar si la infracción penal es consecuencia de la "anomalía o alteración psíquica", es decir, para lo que nos interesa ahora, si las conductas ilegales del fanático son consecuencia o no de su fanatismo.

Ortega-Monasterio ${ }^{24}$ afirma que el criterio de causalidad supone que sin la existencia de la alteración no se hubiera realizado determinada conducta antinormativa y objeta que con ello, en realidad, tal relación causa-efecto se trata de una suposición pues se desconoce si se hubiese cometido la conducta imputable en ausencia de esa anomalía. Esta relación, prosigue el autor, es más un cierto grado de probabilidad que de causalidad.

En este sentido y desde un punto de vista estrictamente empírico, creemos que en un sujeto dogmático, intransigente, desconfiado, en permanente estado de alerta, hostil, con fuerte asertividad, dominante que pretende imponer sus creencias, duro y despreciativo, con escasa empatía hacia los otros y falta de remordimientos, cuya actividad está regulada por la extrapunitividad al considerar a los demás responsables de los males propios ${ }^{2}$ y que asume la ética de la violencia ${ }^{3}$, las probabilidades de aparición de cualquier conducta destructiva son muy altas. No en vano, asegura Echeburua que el fanatismo lleva en sí el germen de la violencia ${ }^{13}$.

Por otro lado, diversas hipótesis vinculan las creencias fanáticas con conductas violentas. Así, García de $\mathrm{Haro}^{6}$ sostiene que las creencias van asociadas a programas instintivos de territorialidad, por cuanto el territorio es un espacio de confianza, fuera de él, prosigue el autor, está lo peligroso, los enemigos, lo desconocido, en lo que no se puede confiar, por lo que despierta temor y agresividad. Montero ${ }^{17}$, a su vez propone que la conducta violenta en terroristas posee un anclaje en estructuras cognitivas específicas que incorporan esquemas encapsulados formados por creencias y actitudes, configuraciones perceptivas, estados afectivos y fisiológicos y protocolos de acción (scripts).

Sin embargo, como asegura de la Corte $^{1}$, el fanatismo sólo puede quedar necesariamente vinculado a aquella clase de comportamientos, interpretaciones y distorsiones que sean congruentes con el contenido de las creencias o ideologías fanatizadas. Por tanto, creemos que sólo se puede encontrar un nexo de causalidad entre el fanatismo y determinadas conductas antijurídicas cuando éstas sean consecuencia de las propias creencias fanáticas. En efecto, pues no todas las conductas del fanático derivan necesariamente de este aspecto de su personalidad, como reconocen Montero ${ }^{17}$ cuando habla de la "compartimentalización conductual" y Alonso Fernández² al explicar la doble parcialidad del fanatismo combativo, ya que éste no abarca al conjunto de la personalidad sino sólo un sector de ella y porque, a lo largo del tiempo alteran fases fanáticas de apaciguamiento o suspensión con otras de encendido y actividad.

\section{Conclusiones}

Hemos tratado de exponer los elementos que, a nuestro entender caracterizan al fenómeno del fanatismo, que podemos resumir en dos: $1^{\text {a }}$. Bidimensionalidad, por cuanto afecta a dos esferas diferentes, aunque íntimamente relacionadas, como son la cognitiva y la personológica y $2^{\mathrm{a}}$ la gradualidad del fanatismo que supone un continuum entre las ideas y las creencias como aspectos normales y las ideas sobrevaloradas e incluso delirantes, como aspectos patológicos. 
En segundo lugar hemos analizado, atendiendo a esta doble dimensión, como el alejamiento de la realidad y/o a la rigidez e inadaptación de la personalidad del

\section{Bibliografía}

1. de la Corte Ibáñez L. La lógica del terrorismo. Madrid: Ed. Alianza Editorial 2006.

2. Alonso-Fernández F. Fanáticos terroristas. BarceIona: Ed. Salvat Contemporánea 2002.

3. Alonso-Fernández F. El fanatismo y sus remedios. Psicopatología. 1995;15(4):191-7.

4. Javaloy F. Introducción al estudio del fanatismo. Barcelona: Ed. Universidad de Barcelona 1984.

5. Ortega y Gasset. Ideas y creencias. Madrid: Ed. Alianza Editorial 2006.

6. García de Haro F. El secuestro de la mente. Madrid: Ed. Espasa 2006.

7. Millon T. Trastornos de la personalidad. Más allá del DSM-IV. Barcelona: Ed. Masson 2000.

8. Berkowiez L. La clínica de los ideales: de la declinación al fanatismo. Asociación psicoanalítica argentina. 2 de septiembre de 2008. Disponible en: http://www.apa.org.ar/foros form. php?id=12.

9. Sánchez Sánchez T. Paradojas existenciales y emocionales de las personas fanáticas. Clínica y Salud. 2003;14:157-81.

10. Ramírez Coronel A. Las creencias y su relación con el estado mental del individuo. Octubre de 2007. Disponible en: www.medwave.cl/instituciones/clinicapsiquiatrica/

11. Díez Patricio A. Psicopatología de la interpretación delirante. Revista de la Asociación Española de Neuropsiquiatría 2003;87:85-100.

12. Fromm E. El miedo a la libertad. Barcelona: Ed Paidos Studio 1989.

13. Echeburua E. Raíces psicológicas del fanatismo político. Análisis y modificación de conducta. 2004;30(130):161-76. fanático pueden afectar a las capacidades cognitiva y volitiva y modificar, por tanto, la responsabilidad de estos sujetos en algunas de sus conductas ilícitas.
14. Elizagárate E. Enfermos no, fanáticos. Mobbing opinión. 14 de marzo de 2004. Disponible en: http://www.mobingopinion.bpweb.net/artman/publish/article 1085.shtml.

15. Echeburua E. Por qué y cómo se llega a ser terrorista. Papeles de Ermua on-line $\mathrm{n}^{\circ} 2$ 2. Disponible en: http://www.papelesdeermua.com/html/modules.php $? \mathrm{op}=$ modload\&name $=$ News\&file $=$ article $\&$ sid $=110$ $\&$ mode $=$ thread $\&$ order $=0 \&$ thold $=0$.

16. Carrasco Gómez JJ, Maza Martín JM. Manual de Psiquiatría Legal y Forense. Madrid: Ed. La Ley 2003.

17. Montero Gómez A. Una hipótesis psicológica sobre los correlatos neurocognitivos de la violencia sistemática del terrorismo. Psicopatología clínica, legal y forense. 2003;3(1):87-99.

18. Villarejo Ramos A. Reflexiones sobre la imputabilidad de los trastornos de la personalidad. Cuadernos de Medicina Forense 2001;24:25-30.

19. Delgado Bueno S, Esbec Rodríguez E, Rodríguez Pulido F, González Rivera y Revuelta JL. Psiquiatría Legal y Forense. Madrid: Ed. Colex 1994.

20. Álvarez JM. La invención de las enfermedades mentales. Madrid: Ed. Gredos 2008.

21. Calcedo Ordóñez A. Pasiones y Paranoia. Cuadernos de Derecho Judicial 1995:291-313.

22. García Andrade JA. Psiquiatría criminal y forense. Madrid: Ed. Centro de estudios Ramon Areces S.A. 2003.

23. Martín Cordero. Psicopatología del delirio II. Medwave. Mayo 2005. Disponible en: http:///www.medwave.cl/cursos/esquizofrenia/4/1.act $<$.

24. Ortega Monasterio L. Psicopatología jurídica y forense. Barcelona: Ed. Promaciones y publicaciones universitarias 1991. 